\begin{tabular}{|c|l|}
\hline Title & Gatsby's Green Light as a Traffic Signal : F. Scott Fitzgerald's Motive Force \\
\hline Author(s) & Takeuchi, Y asuhiro \\
\hline Citation & $\begin{array}{l}\text { F. Scott Fitzgerald review, 14,198_214 } \\
\text { https://doi.org/L0.5325/fscotfitzrevi.14.1.0198 }\end{array}$ \\
\hline Issue Date & 2016 \\
\hline Doc URL & http://hdl.handle.net/2115/65155 \\
\hline Type & article(author version) \\
\hline File Information & Takeuchi_Fitzgerald_Review_Revised052216.pdf \\
\hline
\end{tabular}

Instructions for use 


\section{Gatsby’s Green Light as a Traffic Signal: F. Scott Fitzgerald’s Motive Force}

Citing the critical work on F. Scott Fitzgerald's use of vehicles in The Great Gatsby over twenty years, Jackson R. Bryer declared in 1984 that critics had "more than fully discussed the topic of car, boat, and train imagery” (121). The articles that Bryer cites (and also the subsequent studies) commonly seem to treat vehicles as symbols representing themes in the novel. For instance, consider Leo Marx’s observation that, “[a]s it happens, the car proves to be a murder weapon and the instrument of Gatsby’s undoing. . . . [T]he machine represents the forces working against the dream of pastoral fulfillment” (358). Marx’s juxtaposition of the automobile against the pastoral remains influential even today. Laura Barrett's recent study claims that automobiles represent “an urban, mechanized world” as opposed to "an old world of virgin land” (164)—simply put "the invention of a new mode of human subjugation” (165). Brian Abel Ragen, on the other hand, sees automobiles in the novel as a symbol of freedom, and highlights the link between Gatsby's collapse and the fatal accident at the end, saying: "Gatsby is destroyed after his car is wrecked" (86). Whatever symbolism the automobiles may bear, critics' interest in it seems to have been originally stimulated by Malcolm Cowley, who in 1953 observed, “The characters are visibly represented by the cars they drive; Nick has a conservative old Dodge, the Buchanans, too rich for ostentation, have an 'easy-going blue coupé,’ while Gatsby’s car . . . is West Egg on wheels” (xx). A similar idea is repeatedly expressed by Robert A. Corrigan ("Fitzgerald chose the cars of his characters carefully with symbolic intention” [157]) and by Dan Seiters, who defines the function of the vehicles in Fitzgerald’s fiction as "a characterizing device” (59).

Vehicles for Fitzgerald, however, may be more than just symbols-whether they represent urbanization, freedom, or whatever. Rather, the plot of the novel itself is structured 
around vehicles' movement and stoppage. The vehicles actually serve as the accelerator or the brake to the plot: a series of seemingly incidental yet interweaving details related to vehicles in various scenes strongly suggests that it is their movement or non-movement that creates and destroys the world of Gatsby. However, the way in which the dynamics of mobility and immobility fundamentally sustain the structure of the novel has yet to be explored in detail.

Before we consider the novel in more detail, it is worth reviewing the plot of Tender Is the Night, which also sees Fitzgerald using vehicles to play a vital structural role beyond their supposed symbolic function. Initially, as a bachelor, Dick Diver rides a bicycle (169), but he is soon forced to give it up because of a request by Nicole’s sister, Miss Warren: "Can you let Nicole ride as far as Zürich with you . . . and drop her at the sanitarium?” (180). Dick’s reaction centers on the incompatibility of his bicycle and the train: "Dick was furious-Miss Warren had known he had a bicycle with him; yet she had so phrased her note that it was impossible to refuse. Throw us together!” (180). In spite of his indignation, however, by the end of the "ride in a train” (181) with Nicole, Dick understands that "her problem [her mental illness] was one they had together for good now” (181). Thus, he marries her, but their marriage and their sense of togetherness (“Dick and Nicole had become one and equal” [217]) suffer a treacherous blow when Nicole's "mad hand clutching the steering wheel” (218) wrests their car out of Dick's control—the extreme and hazardous oneness of their relationship is expressed by their both using the one steering wheel. Their car accident illustrates one case where the use of vehicles is structurally vital to Fitzgerald's fiction, beyond any mere significance as a trope, because the accident turns out to be the pivotal moment of the novel—Dick decides to leave Nicole immediately afterward. Later, their temporary separation ends up in a divorce, which may be attributed to their 
accidental reunion with Tommy Barban on "the motor yacht" (300); this transition also coincides with Nicole's recovery, which is suggested appropriately enough by her insistence that she drive on her own, against Dick’s protest: “You haven’t driven for months” (323). Nicole indeed proves she can drive, and she comes to enjoy "a sense of being cured and in a new way" (323) while driving. At the end of the novel, it is briefly mentioned that Dick is somewhere in a small town in the state of New York and that "he bicycled a lot” (352). Thus Dick finally circles back to his bicycle/bachelorhood.

In the same way, the romance between Gatsby and Daisy is essentially ended with the car accident in which Myrtle Wilson is killed; concurrently, the romance of Nick and Jordan also concludes with Jordan's comment about a bad driver: intending to bring their relationship to a close, she says to Nick, "You said a bad driver was only safe until she met another bad driver? Well, I met another bad driver, didn’t I?” (138). What may be less obvious is that the beginnings of both relationships are also depicted as closely linked to vehicles or boats. When Gatsby and Daisy are first witnessed together, they are sitting in a car. Jordan recalls the incident later: "When I came opposite her house that morning her white roadster was beside the curb, and she was sitting in it with a lieutenant I had never seen before” (59). Vehicles similarly form a romantic background for Nick and Jordan: when they kiss for the first time, they are "driving in a Victoria through Central Park” (62). The next instance in which their intimacy is described (“As we passed over the dark bridge her [Jordan's] face fell lazily against my coat’s shoulder” [106]), they are sitting together in Tom's car. Also, when Nick and Jordan were first introduced to each other, Daisy expressed, though playfully, her intention to pair them up using a "boat" as a stratagem: "In fact, I think I'll arrange a marriage. . . . I'll sort of fling you together. You know-lock you up accidentally in linen closets and push you out to sea in a boat, and all that 
sort of thing” (18). There seems to be no exception to this rule where relationships start in vehicles, since Tom's affair with Myrtle also started when they met riding in the same train:

"It was on the two little seats facing each other that are always the last ones left on the train. ... When we came into the station he was next to me ... I was so excited that when I got into a taxi with him I didn’t hardly know I wasn’t getting into a subway train.” (31)

The prospect of Tom and Myrtle's deepening liaison is thus expressed almost solely by their sharing a sequence of the same vehicles.

Gatsby and Daisy, Nick and Jordan, Tom and Myrtle: none of these mobility-borne relationships has much stability. In contrast to them, Tom and Daisy, a married couple, are never depicted sharing the same vehicle throughout the novel. They once come close to both getting in Tom's car to head to Manhattan, but he suggests whimsically at the last moment that he drive Gatsby's car instead, at which Daisy decides to go with Gatsby:

“Come on Daisy,” said Tom, pressing her with his hand toward Gatsby’s car. "I’ll take you in this circus wagon."

He opened the door, but she moved out from the circle of his arm.

"You take Nick and Jordan. We'll [she and Gatsby will] follow you in this coupé.” (94)

Given the suggestiveness of their avoidance of sharing the same car, it seems that vehicles in the novel bear only transient or even illicit relationships.

The irony of the novel is that rather than being founded upon a solid base, the whole dream of Gatsby—as encapsulated in the ephemeral, unrealistic, and illicit romance he conducts with Daisy—is propelled forward or buoyed up by the unstable mobile force. His romantic and 
mobile inclinations, which make him stand out as a unique protagonist, are presented subtly at the beginning of the novel in the form of hypersensitivities to the tremors—-the movements—of the fundamentally stationary world: "[T]here was something gorgeous about him, some heightened sensitivity to the promises of life, as if he were related to one of those intricate machines that register earthquakes ten thousand miles away" (6). Gatsby's "heightened sensitivity" or "romantic readiness" (6) to hope is here equated with a sensitive seismometer that registers even the smallest movements of the earth. Since his dream, his belief in "the unreality of reality" (77), is founded upon the movability of the putatively immovable earth, his youthful reveries are also described aptly as follows:

Each night he added to the pattern of his fancies until drowsiness closed down upon some vivid scene with an oblivious embrace. For a while, these reveries provided an outlet for his imagination; they were a satisfactory hint of the unreality of reality, a promise that the rock of the world was founded securely on a fairy's wing. (77)

For Gatsby, even the solid "rock of the world" has wings, which make the earth movable. These instances might seem to amount only to metaphoric expressions of his extraordinary hopes, if we see Gatsby’s dream only as an ambition to rise in society or obtain the girl of his dreams. Instead, however, he could be taken more literally: his dream is to move something immovablesomething that the unattainable Daisy later embodies.

The epigraph also suggests this insight: "Then wear the gold hat, if that will move her; if you can bounce high, bounce for her too.” The purpose of these movements of a boy in love is "move her"; the girl of his dreams is "movable” only by his own frenetic motion. If so, it is no wonder the older Gatsby is pleased with the rumor that his mansion is in fantastical motion: 
[T]here was one persistent story that he [Gatsby] didn’t live in a house at all, but in a boat that looked like a house and was moved secretly up and down the Long Island shore. Just why these inventions were a source of satisfaction to James Gatz of North Dakota isn’t easy to say. (76)

Besides the desire to "move” Daisy, we can identify another reason for this satisfaction from his past: the transformation of James Gatz into a new creature was indeed triggered by a boat and a yacht.

James Gatz - that was really, or at least legally, his name. He had changed it at the age of seventeen and at the specific moment that witnessed the beginning of his career-when he saw Dan Cody’s yacht drop anchor over the most insidious flat on Lake Superior. It was James Gatz who had been loafing along the beach that afternoon in a torn green jersey and a pair of canvas pants, but it was already Jay Gatsby who borrowed a row-boat, pulled out to the Tuolomee and informed Cody that a wind might catch him and break him up in half an hour. (76)

His new identity itself is thus founded upon kicking the immobile into motion, not only by sustaining the yacht's mobility but also by launching the row-boat. Then, quite appropriately, when Gatsby for "the first time" calls on Nick, the first noticeable feature of Gatsby for Nick is his "resourcefulness of movement” (51). Admiring Gatsby’s car (“[Gatsby] saw me [Nick] looking with admiration at his car" [51]), Nick again mentions his incessant motion: "He was never quite still” (51).

We can put this another way. When one's vehicle stops and one's forward motion ceases, the magic world that can be conjured up when one remains in motion will necessarily start to 
evaporate, or more accurately, lose its "romantic" motive force and fall into a collision course with reality. As if to reflect this dialectic tension between mobility and immobility, upon which the world of Gatsby is delicately balanced, the names of numerous people who visited Gatsby's mansion during the summer of 1922 are registered by Nick "on the empty spaces of a timetable” (49). The idea of a timetable, or the amassed schedules of the starting and stopping of trains, resonates with Nick's rendition of the events of the summer as ephemeral occurrences in the constant fluctuations of mobility. What Nick felt after the summer, when he "came back from the East last autumn" (5), becomes more meaningful in this sense. He says, "I wanted the world to be in uniform and at a sort of moral attention forever" (5). What Nick expects of his Midwestern hometown as opposed to New York City is to see everything stationary-motionless — expressed as "the world . . . at a sort of moral attention." His departure from New York can be taken as a reaction to the excessive mobility that he has experienced in the East.

As Nick’s use of the phrase "moral attention” signals, his decision to leave the mobility of the East behind seems itself to bear a moralistic aspect. Richard Lehan, for instance, believes that Nick supplies a moralistic element in the novel, which taken as a whole "lacks a moral center" (31). Indeed, Nick calls himself "one of the few honest people” (48), and condemns Gatsby as "represent[ing] everything for which I have an unaffected scorn" (6) and Tom, Daisy and Jordan as "a rotten crowd” (120). Interestingly, it is only after the fatal car accident that Nick brings himself to acknowledge Gatsby's greatness ("You're worth the whole damn bunch put together” [120]). This seems to imply that it is the humbling of Gatsby and the total destruction of his mobility that has allowed Nick to put his moralistic guard down. In addition, before his return to the Midwest, Nick breaks up with a "bad driver" (Jordan) and has his "car sold to the grocer” (140). Nick’s moral standard, therefore, might be summed up as this: excessive mobility 
is immoral.

For Fitzgerald, however, mobility surely remains attractive and inspirational in a way that is irreducible to its immoralistic aspect. The inspiration for his use of mobility in the novel could be sought, at least partly, in the epoch-making introduction of traffic lights, which the Fitzgeralds experienced in New York City in 1920. Sarah Churchwell, in her recent book Careless People, quotes from New Yorkers' complaints in newspaper letters to the editor in 1922 and 1924 about the confusing new traffic signals ("green in this city when displayed on a tower means stop”; “our signal system provides . . . a green signal really for stop” [66]), and draws a parallel between people’s confusion and Gatsby's “misread[ing] the green light when he moves to New York" (66). As Churchwell further notes, "While New Yorkers were writing letters complaining that the meaning of green lights was eluding everyone, Fitzgerald was finishing a novel that is driven by Gatsby's faith in the green light and the promise of progress it seems to make” (66). But in fact, Fitzgerald has not yet started writing the novel when he and his wife first encountered the new traffic signals (and perhaps were baffled by the green light). The first traffic light was installed, on an experimental basis, on Fifth Avenue in February 1920:

Signal towers, twelve feet above the pavement, to be erected on the avenue and Fifty-seventh, Fiftieth, Forty-second, Thirty-eighth and Thirty-fourth Streets, each equipped with telephones and push-button signals and flashlights, will direct traffic. In place of the familiar red and green "stop” and "go” semaphore signals, drivers must accustom themselves to red, yellow and green traffic tower signals. (“Fifth Av. Traffic”)

Soon after the first experimental installment of the traffic towers, a column in The New York Times on 15 March 1920 describes the joyful atmosphere created by the new traffic lights: 
New toys are always acceptable whether they are obviously intended for children or ingeniously disguised so as not to offend the dignity of adults, but it has been a long time since New York has had a toy with such infinite possibilities as the traffic tower stations on Fifth Avenue. The way the public has taken up the new game of red, yellow and green lights must assuredly have exceeded the fondest hopes of the inventor. The idea of the thing is quite simple and, what is more, it is thoroughly democratic. Everybody has to play whether he likes it or not. Pedestrians, trucks, automobiles—-they must all play the game of the lights. ("The Traffic Lights”)

Significantly enough, less than three weeks later on 3 April 1920, and on the same avenue, in the rectory of St. Patrick's Cathedral on Fifth Avenue, Fitzgerald married Zelda Sayre (Bruccoli 144). And that summer, the Fitzgeralds embarked on the automobile expedition whose account was published as “The Cruise of the Rolling Junk” in MOTOR: The National Magazine of Motoring, in three installments from March to May in 1924, the same year Gatsby was being written. ${ }^{1}$ The opening part of "Rolling Junk" suggests Fitzgerald’s aspiration to movement as opposed to stationariness:

To be young, to be bound for the far hills, to be going where happiness hung from a tree, a ring to be tilted for, a bright garland to be won-It was still a realizable thing, we thought, still a harbor from the dullness and the tears and disillusion of all the stationary world. (58)

The above passage may remind us of Gatsby a moment before he first kisses Daisy. Like Gatsby, Fitzgerald feels as if he could leave the earth behind and climb up the ladder to heaven, where "he could suck on the pap of life, gulp down the incomparable milk of wonder" (86). In order to 
escape from "the stationary world" and go where "happiness hung from a tree," Fitzgerald pushed down the accelerator.

Thus, on the one hand, Fitzgerald is fascinated with mobility; on the other, however, Nick by the end of the novel is fed up with it. This disjunction between the character and his author might be the reason Fitzgerald depicts Nick's attitude toward Tom in a way that appears morally ambiguous to readers like Lehan. Highlighting the fact that Nick finally shakes hands with Tom, although the latter remains an embodiment of ignorance and carelessness ("I shook hands with [Tom]; it seemed silly not to, for I felt suddenly as though I were talking to a child [139-40]), Lehan finds Nick’s ““what’s the use attitude”” (106) baffling. Further, Lehan raises a question about Nick’s departure from New York: “[I]s a retreat to the world of his father's hardware store the answer to this situation?” (106). Most likely, Lehan’s confusion comes from the double aspect inherent in Nick’s departure from the East, namely, that Fitzgerald has forced Nick to deal here with moral issues and the problem of mobility simultaneously. Nick's breakup with Jordan and growing disregard for what the East represents should not be seen solely as a moral choice, but also as a departure from excessive mobility (which is, of course, immoral for him). He dumps the "bad driver" and disposes of his own car after the fatal crash, and retreats, not necessarily to the hardware store, but certainly to his own stationary (therefore moralistic) world.

Along the same lines, we as readers might well reserve moral judgments and focus on issues of mobility in the various instances when a character in the novel moves something that is supposed to remain static. The priority of mobility over morality is exemplified by Jordan, a professional golfer with a morally dubious past: “At her first big golf tournament there was a row that nearly reached the newspapers — a suggestion that she had moved her ball from a bad lie in 
the semi-final round" (47). This instance of excessive "mobility" could be more significant than meets the eye, in that Jordan actually serves as our key person for understanding Gatsby as a novel of mobility. First of all, her name, Jordan Baker, is the combination of the name of a car manufacturer, the Jordan Motor Car Company, and either the Baker Electric, “a short-lived car made around the turn of the century" (Corrigan 156) or "Baker 'Fastex' Velvet, a luxury upholstery fabric for automobiles” (MacPhee 208). In either case, Jordan's relation to automobiles seems beyond doubt. MacPhee further points out that "Nick sandwiches [the episode of Jordan's cheating at golf] between two references to automobiles” (209). One reference is to Jordan's leaving a borrowed car in the rain with the top down, and the other concerns her near miss with a workman while driving. Both of these automobile-related episodes pose questions about her morality, and we can in turn apply this close thematic relation between automobiles and morality to the case of her cheating in golf. That is to say, Jordan's immoral action—moving the ball—is an instance of extraordinary mobility on the part what is supposed to be static, like Gatsby's "rock of the world.” As mentioned above, Jordan is the one that unintentionally summarizes the whole story with her question to Nick: "Well, I met another bad driver, didn’t I?” Gatsby, in a way, has met an equally bad driver in Daisy.

Moral questions raised by the incidents surrounding the illicit love affairs in the novel can also be reassessed in the light of mobility. If an extraordinary motion can make the unreal or immoral (in Nick's view) real, it is quite natural that such ephemeral, immoral, or unrealistic moments will evaporate when the movement ceases. When a vehicle stops, a romance also stops. If the romance is founded upon fiction (lies, deceits, make-believes), the halt in motion reveals the truth—-truth being something that belongs to the stationary world. That is, the act of stopping brings to the surface some unmovable facts of one's life, such as one's past or one's parentage (in 
short, one's identity), that have hitherto remained unnoticed in the confusion or commotion sustained by rapid mobility.

For instance, the revelation of Tom's affair with "one of the chambermaids in the Santa Barbara Hotel” because of a car accident (“Tom ran into a wagon on the Ventura road one night, and ripped a front wheel off his car. The girl who was with him got into the papers” [61]) is only a small repetition of (or chronologically, a prelude to) a more significant halt in the earlier part of the novel. At the Valley of Ashes, trains have to stop "when the drawbridge is up to let barges through" (21). As Nick describes it, “There is always a halt there of at least a minute, and it was because of this that I first met Tom Buchanan’s mistress” (21). Thus, the halt gives Nick a chance to explore the hidden side of Tom's life; in other words, this is the same chain of events that occurred to reveal Tom's affair with the chambermaid: a vehicle stops and an evanescent relationship sustained by mobility is brought back to reality, and witnessed by others in the stationary world. Later in the novel, the two extramarital relationships-Gatsby-Daisy and Tom-Myrtle-become apparent to each husband almost at the same time, and these two “parallel” (97) discoveries are presented in the text right before and after Tom, in Gatsby’s car, makes a brief stop at Wilson's garage. When “Tom [throws] on both brakes impatiently, and we [Nick, Jordan and Tom] slid[e] to an abrupt dusty spot under Wilson’s sign” (95), Tom is furious because he has just realized that his wife is having an affair; and they soon find Wilson extremely distressed as well, because he "had discovered that Myrtle had some sort of life apart from him in another world" (96).

Contrary to Tom, Gatsby, driving Tom's coupé with Daisy, does not stop at the garage: “The coupé flashed by us with a flurry of dust and the flash of a waving hand” (96). Moreover, it is this sustained movement that prevents Myrtle from knowing the truth; she mistakes Jordan for 
Tom's wife and fatally confuses Gatsby’s car with Tom’s. If Gatsby had stopped at the garage, the reality would have been revealed to Myrtle and she could have avoided her misunderstanding. On their way back from Manhattan, Gatsby and Daisy again fail to stop when they run over Myrtle: “The 'death car,' as the newspapers called it, didn’t stop” (107); and this time Wilson loses his chance to learn the reality: not knowing exactly with whom his wife has had an affair, he is led by his confusion to shoot Gatsby. Fitzgerald makes this point by reiterating that Gatsby’s car did not stop: “Son-of-a bitch didn’t even stopus car” (109), says the policeman; "the car passed me down the road, going faster'n forty. Going fifty, sixty” (109), says a witness; “He didn’t even stop his car” (111), says Tom in anger. To Michaelis, who is attending to the distraught George, every passing car sounds “like the car that hadn’t stopped a few hours before” (122). It is this never stopping, this excessive mobility, that pulls Myrtle and George so far away from a clear perception of reality as to allow their fateful misunderstandings.

In this light, the tragic ending of the novel is also an ironic one, since the selfsame mobility that is the very moving force for Gatsby's romance also leads to his demise. The never-stopping car may even remind the reader of the central motif of the novel: the green light at Daisy’s dock. The traffic light for Gatsby’s car, so to speak, may also always be "green.” Quite suggestively, Michaelis testifies to the policeman that the color of the car that did not stop was "light green” (107), while in reality Gatsby’s car had “a rich cream color” (51). ${ }^{2}$ This seemingly trivial mistake aligns the accident even close with the perpetual forward motion symbolized by the green color. It may seem merely ironic that Gatsby's dream girl, the embodiment of the "green light," turns out to be a bad driver who does not know when to stop. (Gatsby admits, "I tried to make her stop, but she couldn't, so I pulled on the emergency brake” [113]). But, of course, it is the excessive and "immoral" movement, not a brake, that Fitzgerald needed as a 
writer to leave the stationary world behind.

The nature of Gatsby's dream and its end can be thus understood in light of the dynamism of mobility and immobility. But the novel still has a few chapters remaining before its famous ending with Nick’s comment, quite suggestively for our argument, evoking boats—“So we beat on, boats against the current, borne back ceaselessly into the past” (141). Let us then extend our reading of Gatsby's life back to the moment of his "borrowing a boat" (the moment of his transformation from James Gatz into Jay Gatsby) and also forward after his death, into the aftermath of his tragic car accident. If his death constitutes an end of mobility, what follows his death will necessarily be a restoration of immobility of some kind. This immobility, I argue, is represented by the new character who appears in the concluding part of the novel: Gatsby's father, whom he had left behind in Minnesota but who now shows up in New York to attend his son's funeral. And it is the father, “a solemn old man very helpless and dismayed, bundled up in a long cheap ulster” (130), who unwittingly dispels his son’s persona and reveals Gatsby’s real name and history. If Gatz's transformation into Gatsby is "his imaginative re-creation of himself [, which] is compared to deific autogenesis” as John T. Irwin argues (77), then his hope to be "his own grandson" or "his own son as well” (Irwin 77) is to be denied once for all by the appearance of his biological father-quite appropriately, for his funeral. In a broader sense, the immobility, or the counter-force that has borne Gatsby back from his dream life of mobility and pro-motion, is his low blood and breeding, a representation of the ultimate stationary world that one cannot leave behind-unless one can change the past.

Fitzgerald seems to have prepared this ending, an introduction of Gatsby’s father as an embodiment of de-motion, by interrelating mobility and breeding in the earlier parts of the novel. 
For instance, back when Nick, having learned Gatsby’s extraordinary past, is still uncertain about Gatsby’s identity, he witnesses a scene of racial subversion from Gatsby’s car:

As we crossed Blackwell's Island a limousine passed us, driven by a white chauffeur, in which sat three modish Negroes, two bucks and a girl. I laughed aloud as the yolks of their eyeballs rolled toward us in haughty rivalry.

“Anything can happen now that we've slid over this bridge,” I thought; "anything at all...."

Even Gatsby could happen, without any particular wonder. (55)

This is overtly a racially loaded scene, to which Benjamin Schreier notes "[r]ecent criticism of the novel's interest in race frequently turns" (177). But we should note that Nick does not fail to mention Gatsby to conclude his comments, suggesting an analogy between these affluent African Americans and Gatsby's glamourous persona. Although Nick attributes this incident to their crossing the bridge into Manhattan, it may in fact be the two automobiles, the limousine and Gatsby's car, that enable anything to happen. Putting aside the argument of whether or not Nick is a nativist, Schreier's overall criticism of "the racialist premise that race is physical, biological, or otherwise anchored in the body" (162) helps us understand, beyond his own argument, that racial subversion can also be seen in terms of mobility, as his term "anchor" connotes. What seems at issue in the scene, therefore, is the sense of excessive mobility surmounting the unchangeable past and breed/race/origins, the sweeping mobility demonstrated by both Gatsby's talk during the drive about his incredible past and the encounter with the limousine passengers.

Indeed, prior to this incident, a similar (yet contrasting) encounter-when Nick is on his way to Manhattan in a taxicab with Tom and Myrtle—-has already posed the question of breeding. When Myrtle orders their taxi to stop (a countermove against mobility) to buy a dog from an old 
man selling puppies on the street, the dog's breed becomes problematic.

But immediately she [Myrtle] turned sharply from the window and, leaning forward, tapped on the front glass.

"I want to get one of those dogs," she said earnestly. ...

We backed up to a gray old man who bore an absurd resemblance to John D. Rockefeller. In a basket, swung from his neck, cowered a dozen very recent puppies of an indeterminate breed. (24)

Charles Lewis, discussing Gatsby’s ethnic identity, penetrates to the underlying theme of racial "passing” behind the problem of the dog's breed (176-77). The ensuing conversation among Myrtle, Tom, and the dog seller seems to make his point:

“That’s no police dog,” said Tom.

"No, it’s not exactly a police dog," said the man with disappointment in his voice. “It’s more of an Airedale.”

“Is it a boy or a girl?” she asked delicately.

“That dog? That dog's a boy.”

“It’s a bitch,” said Tom decisively. (24)

But what is most important for our purposes is that the near-miss revelation of the dog's breed and sex is happening during the moment of a halt in the taxicab's movement. If mobility has sustained Gatsby's splendid persona throughout the novel, a temporary disruption in the motion of a vehicle could quite logically be a moment of danger for his fake identity—specifically, his fake breed. For instance, when a motorcycle policeman later orders Gatsby’s car to stop, Gatsby escapes the hazardous moment by showing his mysterious identification card (a Christmas card 
from "the commissioner" [54]). Likewise, the halting of the taxicab brings to the surface the problem of the dog's questionable breed and sex. Fitzgerald thus seems to suggest that the essence of stationary reality is one's breeding, whose representations are multifaceted and may vary in different contexts from race, sex, to parentage.

Actually, the theme of the dog's breed, as Lewis notes, soon develops into that of a man's breeding (177). Myrtle brings the dog with its dubious breeding to her apartment in Manhattan, and it is in that apartment, in the presence of the dog, that she starts to complain about her husband, who embodies for her bad breeding: “'I married him because I thought he was a gentleman,' she said finally. 'I thought he knew something about breeding, but he wasn’t fit to lick my shoe”" (30). But significantly enough, her husband, George Wilson, is also characterized throughout the novel as one suffering from immobility.

Wilson is a denizen of a place for halts: the Valley of Ashes, where he runs his garage. As noted earlier, this is a place where trains have to stop: "There is always a halt there of at least a minute” (21). The hazard to mobility inherent in the place is also hinted at by the way automobiles and trains are described as wriggling away from it: “About half way between West Egg and New York the motor-road hastily joins the railroad and runs beside it for a quarter of a mile, so as to shrink away from a certain desolate area of land. This is a valley of ashes” (21). Wilson, barely managing to keep his garage in business in such a place, has been clinging to the hope of obtaining Tom's car and moving away from there. ${ }^{3}$ But as we know, Wilson's dream of mobility is tragically (yet appropriately given the ominous nature of the place for vehicles) shattered by the fatal car accident.

Indeed, it was at this hazardously tricky place for mobility that an incident revealed Wilson's breeding, when a man appeared one day at the garage and asked Myrtle about a suit. 
(Since the Wilsons have "been living over that garage for eleven years" [30], it must be the same garage that the man visited). Myrtle indignantly looks back at the incident:

“The only crazy I was was when I married him. I knew right away I made a mistake. He borrowed somebody's best suit to get married in and never even told me about it, and the man came after it one day when he was out. She looked around to see who was listening: 'Oh, is that your suit?' I said. 'This is the first I ever heard about it.' But I gave it to him and then I lay down and cried to beat the band all afternoon.” (30)

After all, Wilson's dream for mobility, ill-founded on his garage located in this automotive graveyard, was potentially already shuttered eleven years earlier, when the above incident exposed his identity—or his breed. ${ }^{4}$

Considering Wilson's problems of breeding and immobility, Gatsby’s death at his hands and his own suicide become quite suggestive. Indeed, the two men's lives are both parallel (in terms of their breeding) and contrasting (Wilson as the poor immovable man and Gatsby as the rich movable man), shedding further light on another significant contrast between them: Wilson's death as a "self-destruction” (suicide) may hint at the nature of Gatsby’s birth as a self-made man, a "self-creation.” This also confirms Irwin's argument that Gatsby has tried to solve the problem of breeding by recreating himself. But we should not forget that such an extraordinary enterprise has been made possible by his mobility (although it fails in the end for the same reason). Because of this interrelation between mobility and breeding, Gatsby's father, like the man who came to Wilson's door for his suit, appears at the funeral and reveals Gatsby's breeding. The end of mobility for Gatsby, as noted, is the restoration at once of immobility and of breeding. 
Paying critical attention to actual mobility and movement in The Great Gatsby has thus revealed one of the essential structures of the novel—how Gatsby's world is built and sustained by mobility and how it is destroyed by immobility. Also, our argument has at least hinted at the possibility that seemingly unrelated themes of race, class, or breeding can also be understood in terms of representations of immobility as opposed to mobility. But at the same time, our discussion of mobility and breeding necessarily leads us to reexamine one of the most discussed themes of the novel: time. To conclude, let us consider how mobility underlies the problem of time.

One clue is Gatsby's self-disciplined childhood schedule, written on a fly-leaf (134), which his father proudly shows to Nick. The young Gatz's timetable can be seen as a starting point for all his efforts to gain the momentum to move the stationary world-perhaps emulating Benjamin Franklin. However, if his ultimate goal is to replace the "immovable" source of his breeding (his father) with somebody else (such as Franklin or Gatsby himself), such an undertaking is in essence an effort to rewrite (not exactly repeating, but recreating) his own past, an effort that is necessarily at odds with the flow of time. Ironically, then, while the young Gatz founded his ambition on the forward progression of time, planning out a rigid time schedule within and by which to advance himself, the direction he would have needed to take was really backward. He did not seem to understand the paradox that his future, his hope of recreating himself, would never be realized unless he could go back to the past, to the origin of his breeding, to the "orgastic" moment of insemination. In this sense, Nick's final vision of a new origin-the virgin continent witnessed by Dutch sailors—adequately hints at the extraordinariness, the greatness, of Gatsby’s preposterous enterprise.

Gatsby's tragedy is that he thought he could achieve such a self-creation only if he could 
move ever faster, under the aegis of the perpetual green (traffic) light ahead of him: "Gatsby believed in the green light, the orgastic future that year by year recedes before us. It eluded us then, but that's no matter-tomorrow we will run faster . . .” (141). This final comment of Nick's seems to suggest that Fitzgerald understands the irony of time (an irony unnoticed by the young Gatz) to be that of mobility; put another way, he seems to understand Gatsby's hope as an effort to solve the temporal problem by solving the spatial problem-that is, as the hope that if Gatsby can achieve some excessive mobility to take off from the immovable rock of the world, he can also separate himself from the immovable past and recreate it from scratch.

Fitzgerald himself once expressed the problem of breed with subtly reference to a vehicle. ${ }^{5}$ In a letter to John O’Hara describing his feelings toward his ancestry, he writes: “I developed a two-cylinder inferiority complex" (Letters 233). In order to meet "an inner necessity of starting my life and my self-justification over again at scratch” (Letters 234), his two-cylinder engine seems to have run so fast as to make even Gatsby "happen”- the man who desperately strove against the temporal impossibility of becoming the father to his own self, by pushing the possibility of mobility to its extreme. 
Notes

1. For a detailed account of “Rolling Junk,” see Speer 540, and J. Lewis 69.

2. Bufkin notes that both Gatsby and Myrtle stretch their arms out toward the color green: Gatsby to Daisy’s green light and Myrtle to the “light green” car (521).

3. O’Meara also notes that George Wilson’s hope is founded on cars (79).

4. Pointing out the similarities between George and Gatsby, Saposnik sees George as Gatsby's double in that both of them failed in their pursuit of a dream of escape (184).

5. For Fitzgerald's negative view of his upbringing, see Donaldson 2-3, and Irwin 11-14. 


\section{Works Cited}

Barrett, Laura. "From Wonderland to Wasteland: The Wonderful Wizard of Oz, The Great Gatsby, and the New American Fairy Tale.” Papers on Language and Literature 42.2 (2006): 150-80. Print.

Bruccoli, Matthew J., and Scottie Fitzgerald Smith. Some Sort of Epic Grandeur: The Life of F. Scott Fitzgerald. Columbia, SC: U of South Carolina P, 2002. Print.

Bryer, Jackson R. “Style as Meaning in The Great Gatsby: Notes Toward a New Approach.” Critical Essays on F. Scott Fitzgerald's The Great Gatsby. Ed. Scott Donaldson. Boston: Hall, 1984. 117-29. Print.

Bufkin, E.C. “A Pattern of Parallel and Double: The Function of Myrtle in The Great Gatsby.” Modern Fiction Studies 15. (1969): 517-24. Print.

Churchwell, Sarah. Careless People: Murder, Mayhem, and the Invention of The Great Gatsby. New York: Virago Press, 2014.

Corrigan, Robert A. "Somewhere West of Laramie, on the Road to West Egg: Automobiles, Fillies, and the West in The Great Gatsby.” Journal of Popular Culture 7. (1973): 152-58. Print.

Cowley, Malcom. “The Romance of Money,” Three Novels of F. Scott Fitzgerald. Ed. Malcom Cowley. New York: Scribner, 1953. Print.

Donaldson, Scott. Fool for Love—F. Scott Fitzgerald. Minneapolis: U of Minnesota P, 2001. Print.

“Fifth Av. Traffic to Go South from 10 to 5.” New York Times, 6 Feb. 1920. Web. 26 Sep. 2010. Fitzgerald, F. Scott. A Life in Letters. Ed. Matthew J. Bruccoli. New York: Touchstone, 1995. Print. 
. Tender Is the Night. 1934. Ed. James L. W. West III. New York: Cambridge UP, 2012. Print.

. The Cruise of the Rolling Junk. Ed. Matthew J. Bruccoli. Bloomfield Hills: Bruccoli Clark, 1976. Print.

—. The Great Gatsby. 1925. Ed. Matthew J. Bruccoli. New York: Cambridge UP, 1991. Print.

Irwin, John T. F. Scott Fitzgerald's Fiction: “An Almost Theatrical Innocence.” Baltimore: Johns Hopkins UP, 2014. Print.

Lehan, Richard. The Great Gatsby--The Limits of Wonder. Boston: Twayne, 1990. Print.

Lewis, Charles. "Babled Slander Where the Paler Shades Dwell: Reading Race in The Great Gatsby and Passing.” Lit: Literature Interpretation Theory 18.2 (2007): 173-91. Print. Lewis, Janet. “'The Cruise of the Rolling Junk’: The Fictionalized Joys of Motoring.” Fitzgerald-Hemingway Annual (1978): 69-81. Print.

MacPhee, Laurence E. “The Great Gatsby’s ‘Romance of Motoring’: Nick Carraway and Jordan Baker.” Modern Fiction Studies 18. (1972): 207-12. Print.

Marx, Leo. The Machine in the Garden. New York: Oxford UP, 1964. Print.

O'Meara, Lauraleigh. “Medium of Exchange: The Blue Coupe Dialogue in The Great Gatsby.” Papers on Language and Literature 30.1 (1994): 73-87. Print.

Ragen, Brian Abel. A Wreck on the Road to Damascus: Innocence, Guilt, \& Conversion in Flannery O'Connor. Chicago: Loyola UP, 1989. Print.

Saposnik, Irving S. “The Passion and the Life: Technology as Pattern in The Great Gatsby.” Fitzgerald-Hemingway Annual (1979): 181-88. Print.

Schreier, Benjamin. “Desire's Second Act: ‘Race’ and The Great Gatsby’s Cynical 
Americanism.” Twentieth Century Literature 53.2 (2007): 153-81. Print.

Seiters, Dan Loren. “Image Patterns in the Novels of F. Scott Fitzgerald.” Dissertation Abstracts: Section A. Humanities and Social Science 37. (1986): 3629A. Print.

Speer, Roderick S. “The Great Gatsby’s ‘Romance of Motoring’ and 'The Cruise of the Rolling Junk."” Modern Fiction Studies 20. (1974): 540-43. Print.

“The Traffic Lights.” New York Times, 15 Mar. 1920. Web. 26 Sep. 2010. 